\title{
Recent progress in the study of accessory minerals
}

\author{
Lutz Nasdala $^{1}$ • Igor Broska ${ }^{2}$ - Daniel E. Harlov ${ }^{3,4}$ - Ray Macdonald ${ }^{5,6}$
}

Published online: 18 July 2017

(C) Springer-Verlag GmbH Austria 2017

Accessory minerals are a common species in igneous and metamorphic rocks that are not considered characteristic of the host rock and hence do not affect its root name. Accessories tend to be complex in terms of their chemical and isotopic composition and their structural state. In spite of not being major rock constituents, they are, however, of enormous petrologic interest as they contain a record of the formation and post-formation history of their host rock. The study of accessory minerals hence has increased continuously during the past years, and still increases (Fig. 1). Recent progress is driven by new analytical opportunities of (in situ) micro-techniques. More and more the internal textures, that is, elemental, isotopic, and/or structural distribution patterns within individual grains, have come into the focus of researchers; a few examples are compiled in Fig. 2.

The present special issue aims at providing an overview of recent progress in the study of accessory minerals. It was compiled on the occasion of CAM-2017, the Conference on Accessory Minerals (September 13-17, 2017, Vienna,

Lutz Nasdala

lutz.nasdala@univie.ac.at

1 Institut für Mineralogie und Kristallographie, Universität Wien, Althanstr. 14, 1090 Wien, Austria

2 Slovak Academy of Sciences, Earth Science Institute, Dúbravska cesta 9, 84005 Bratislava, Slovak Republic

3 Section 4.3, Helmholtz Centre Potsdam, GFZ German Research Centre for Geosciences, Telegrafenberg, 14473 Potsdam, Germany

4 Department of Geology, University of Johannesburg, P.O. Box 524, Auckland Park, South Africa

5 Institute of Geochemistry, Mineralogy and Petrology, University of Warsaw, 02-089 Warszawa, Poland

6 Environment Centre, Lancaster University, Lancaster LA1 4YQ, UK
Austria). This conference was a follow-up of the Workshop on Accessory Minerals (September 25-26, 2014, Warsaw, Poland), organised by Ray Macdonald and Bogusław Bagiński.

The continuing interest in accessory mineral research is also underlined by the fact that Mineralogy \& Petrology released a special issue "Accessory minerals in igneous and metamorphic rocks" just six years ago (vol. 102; October, 2011). The present special issue, devoted to the very same topic, contains 13 research articles. Even though zircon seems

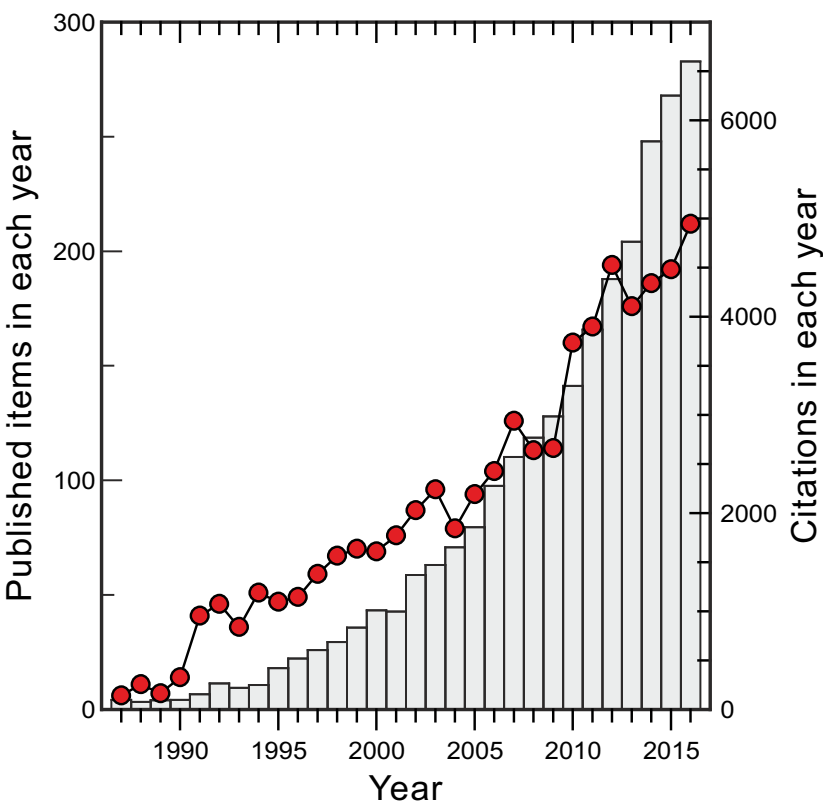

Fig. 1 Publications referenced in the WoS (Web of Science; Thomson Reuters ${ }^{\mathrm{TM}}$ ) whose topic contains "accessory" and "mineral". The search was limited to the four research areas of geology, geochemistry, mineralogy and crystallography, for the last 30 years (1987-2016). Red circles, number of publications in each year; underlying grey histogram, number of citations in other WoS publications 

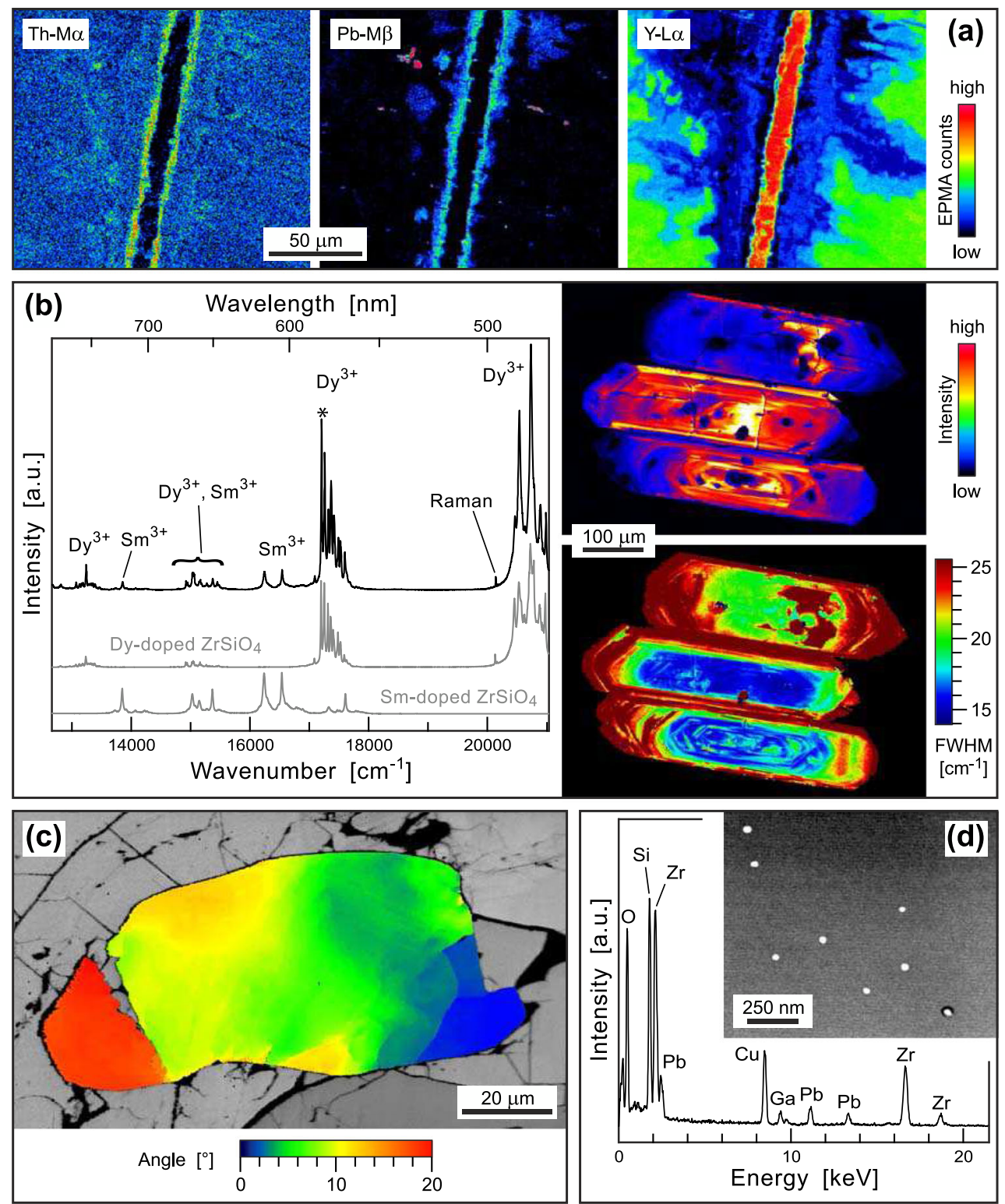

Fig. 2 Four examples of diverse analytical studies of accessory minerals. a Electron probe micro-analyser (EPMA) chemical mapping of metamict fergusonite from Berere, Madagascar, that suffered chemical alteration near a fracture (centre). Thorium and $\mathrm{Pb}$ are enriched adjacent to the fracture whereas $\mathrm{Y}$ is depleted; the fracture filling itself is $\mathrm{Y}$ rich. Sample courtesy C. Schnier, analyses D. Rhede. b Photoluminescence (PL) spectrum of zircon from the Gold Butte block, Nevada, with reference spectra of flux-grown, Dy- and Sm-doped $\mathrm{ZrSiO}_{4}$. Colourcoded images of a group of three crystals were generated from hyperspectral mapping of the $17,210 \mathrm{~cm}^{-1}$ line (marked with an asterisk), which belongs to the crystal-field-split ${ }^{4} \mathrm{~F}_{9 / 2} \rightarrow{ }^{5} \mathrm{H}_{13 / 2}$ transition of $\mathrm{Dy}^{3+}$. The two images visualise distribution patterns of Dy

to continue the prime accessory mineral being studied, the present issue presents a fairly broad range of species investigated and topics covered. Breiter and Škoda have studied $\mathrm{Zr} /$ Hf ratios of accessory zircon grains and their host rocks in the Teplice caldera, and they found $\mathrm{Hf} / \mathrm{Zr}$ values to be sensitive indicators of fractionation in the granitic melt. Shumlyansky concentration (increasing intensity) and radiation damage (increasing FWHM, full width at half maximum), respectively. Sample courtesy P.W. Reiners and C. Lenz, analyses C. Chanmuang. c Electron backscatter diffraction (EBSD) map of a zircon in polycrystalline sillimanite from the Val d'Ossola, Italy, highlighting lattice misorientation with respect to a reference point in the lower right of the grain. Sample courtesy E. Kovaleva, analysis G. Habler. d High-angle annular dark field (HAADF) image of a zircon from the Mount Sones paragneiss, Enderby Land, Antarctica, showing several $\mathrm{Pb}$ nanospheres (bright), along with an energy-dispersive X-ray (EDX) spectrum. Sample courtesy M.A. Kusiak, analyses R. Wirth

et al. found that accessory zircon in gabbroic rocks from the Ukrainian Shield has unusually high concentrations of REEs (rare earth element) and other non-formula elements - which they assign to growth from residual melts enriched in incompatible elements - whereas zircon from a pegmatite, in contrast, is depleted in such trace elements. A rather extreme, 
radiation-damaged zircon from the Ural Mountains, with interior regions whose $\mathrm{UO}_{2}$ content exceeds $10 \mathrm{wt} \%$, was studied by Zamyatin et al. The zircon's internal zoning is assigned to diffusional and fluid-driven alteration processes; one of them likely has led to the formation of uranyl that is detected in Raman and PL (photoluminescence) spectra. Other actinide-rich and radiation-damaged species, namely zirconolite and the pyrochlore-supergroup mineral oxycalciobetafite, from Adamello, Italy, are described by Lumpkin et al., who found that both minerals have retained the actinides for 40 myr despite having undergone high selfirradiation on the order of $10^{19} \alpha / \mathrm{g}$. Variations in the composition of "silicate apatites" (i.e. minerals of the britholite group) from pegmatites in the Keivy province, Kola peninsula, allowed Zozulya et al. to unravel large changes of physicochemical conditions in the fluid. Macdonald et al. demonstrate the different susceptibilities of different accessory species to secondary alteration under hydrothermal conditions, for example a quartzolite from Rova, Kola peninsula, Russia. These authors found that zircon underwent stronger alteration, when compared to chevkinite-(Ce), monazite-(Ce), and fergusonite-(Y), and they discuss the importance of fractures as migration pathways for alteration fluids. The paper of Betkowski et al. is devoted to accessory phosphate species in the Sn porphyry deposit near Llallagua, Bolivia. These authors use the accessories in unravelling the formation, and post-formation alteration, history of the deposit. Elliott et al. describe accessory REE-bearing minerals, magnetite, zircon, Fe-rich biotite, and hematite from the Round Top laccolith, Texas. These authors assign the sequential enrichment of the REE (and other incompatible elements) by the prolonged removal of compatible elements in the source magma. Hydrothermally formed titanite from the Fe-skarn deposit of
Chengchao, Daye district, China, is characterised by $\mathrm{Hu}$ et al., who propose that this mineral, whose common- $\mathrm{Pb}$ content is negligible, be used as a reference material in $\mathrm{U}-\mathrm{Pb}$ geochronology. Bačík et al. discuss chemical peculiarities including substitution mechanisms, and formation details, of tourmaline-group minerals in Sb-bearing hydrothermal veins from Slovakia. Tourmaline-group minerals, in this case from pegmatites, are also the subject of Novák et al. The authors found that elevated $\mathrm{Mg}$ contents in these minerals originate from serpentinite host rocks and hence record external contamination of evolved acidic pegmatite melts. Finally, accessory borate minerals with significant internal zoning, originating from a Mg-rich skarn deposit in the Štiavnica stratovulcano, central Slovakia, were studied by Bilohuščin et al. The composition of these borates provides a record of skarn evolution during contact-metasomatic to late hydrothermal stages.

This special issue on accessory minerals could not have been accomplished without the hard, voluntary work and constructive input of peers. We kindly thank the following experts in the field, who spent time and effort on reviewing contributions: Paul Bédard, Elena Belousova, Eleanor Berryman, Robert Bolhar, Karel Breiter, Ian Campbell, Barrie Clarke, Artur Deditius, Brent Elliott, Andreas Ertl, Friedrich Finger, Evgeny Galuskin, Edward Grew, Craig Grimes, Darell Henry, Callum J. Hetherington, Peter Kodera, Monika A. Kusiak, Libing Liao, Ulf Linnemann, David London, Emily M. Peterman, Igor Petrik, Adam Pieczka, Nicholas Pingatore, Jonathan Price, Kamal Pruseth, Anne-Magali Seydoux-Guillaume, Peter Tropper, Pavel Uher, Satoshi Utsunomiya, Marieke van Lichtervelde, Silvio Roberto Farias Vlach and Rucheng Wang. 